\title{
DA INVESTIGAÇÃO E SUAS DESCONSTRUÇÕES OU QUANDO AS AÇÕES DE UMA CRIANÇA SÃO IDENTIFICADAS COMO INSUBORDINAÇÃO
}

\section{ON INVESTIGATION AND ITS DECONSTRUCTIONS OR, WHEN A CHILD'S ACTIONS ARE IDENTIFIED AS INSUBORDINATE}

\section{Luzia Aparecida de Souza}

Universidade Federal de Mato Grosso do Sul (UFMS) / luapso@gmail.com

\section{Vivian Nantes Muniz Franco}

Universidade Federal de Mato Grosso do Sul (UFMS) / viviannmfranco@gmail.com

\section{Resumo}

Este trabalho apresenta algumas percepções e considerações acerca de uma entrevista realizada como um primeiro movimento de uma pesquisa de mestrado que busca compreender como as crianças espacializam a escola na Educação Infantil e de que modo significam a matemática neste espaço por meio da construção de narrativas com crianças de 4 e 5 anos. Inicialmente foram mobilizados procedimentos da História Oral, na perspectiva de construir fontes históricas a partir de situações de entrevista. O movimento tem se dado na direção de construir e analisar narrativas e suas contribuições para se pensar a temática da pesquisa e a própria ação de pesquisar. A partir de uma entrevista realizada com o Francisco, de 4 anos, trazemos algumas reflexões com as quais pretende-se tratar de aspectos teóricos e metodológicos que permeiam uma pesquisa dessa natureza, assim como, olhar para como a entrevista com uma criança nos atravessa enquanto pesquisadores e pode nos ensinar sobre insubordinação e/ou movimento investigativo.

Palavras-chave: Pesquisa. Narrativas infantis. Insubordinação criativa.

\begin{abstract}
Current paper forwards some perceptions and considerations on an interview taken as a first phase in a Master's Degree research on the manner children organize the space of the fundamental school and how 4 - 5-year-old children give meaning to Mathematics within this space through the building of narratives. Oral History was first endeavored to build historical sources from situations given in the interview. The movement then proceeded to build and analyze narratives and their contribution for the selection of the research's theme and on the research itself. The interview with 4-year-old Francisco triggered reflections on the theoretical and methodological aspects which will be dealt with.
\end{abstract}


The interview with the child shows our involvement as researchers and gives us clues on insubordination and/or the investigation stance.

Keywords: Research. Children's stories. Creative insubordination.

\section{Um início...}

Sempre compreendo o que faço depois que já fiz. O que sempre faço, nem seja uma aplicação de estudo.

É sempre uma descoberta. Não é nada procurado. É achado mesmo. (Barros, 2010, p. 85)

Este texto trata de uma pesquisa de mestrado que tem como objetivo compreender como as crianças espacializam a escola na Educação Infantil e de que modo significam a matemática, por meio da construção de narrativas com crianças de 4 e 5 anos, que frequentam a creche e a pré-escola.

Vinculada ao grupo HEMEP - História da Educação Matemática em Pesquisa1, essa proposta colocou-se na perspectiva de um trabalho com narrativas de crianças e um primeiro movimento, mais próximo aos estudos do grupo, foi feito em relação aos procedimentos da História Oral. Assim, este artigo trata não do que pode, mas do que efetivamente pôde uma primeira e única entrevista com Francisco, de 4 anos, quando consideramos o incômodo e a/pela multiplicidade de desestabilizações que a situação nos proporcionou. É importante ressaltar que Francisco estuda em uma escola privada, bilíngue, desde os seis meses de idade e participou de uma primeira entrevista sobre esse espaço por conta da necessidade de se pensar a narrativa nesse contexto e pela sua proximidade, como filho da orientadora dessa investigação.

Trata-se da sinalização para a necessidade de subvertermos métodos, procedimentos e caminhos previamente traçados, ou melhor, trata-se da percepção de que, embora sustentássemos um discurso de pesquisa em construção, ainda praticávamos o movimentar-se por um caminho e não o colocar-se aberto a experimentar uma travessia.

Nessa direção, dialogamos com a perspectiva acerca de manifestações de insubordinações criativas de pesquisadores,

Ao pensarmos sobre as manifestações de insubordinações criativas dos pesquisadores, verificamos que elas têm se constituído pelos questionamentos feitos: posicionamentos metodológicos rígidos; perspectiva avaliativa da produção do outro; incoerências entre práticas e relatos de pesquisas; ação política contraditória ao discurso; critérios aleatórios utilizados para avaliar a qualidade da produção científica; distribuição de verbas para produção científica; avaliação quantitativa das publicações; posição do pesquisador como intelectual (dono do saber) nos

\footnotetext{
${ }^{1}$ Grupo cadastrado no Conselho Nacional de Desenvolvimento Científico e Tecnológico (CNPq) e certificado pela Universidade Federal de Mato Grosso do Sul (UFMS).
} 
relacionamentos entre professor e aluno e pesquisador e sujeito. (D'AMBRÓSIO e LOPES, 2015, p. 4).

Ao discutirmos metodologia de pesquisa como resultado de uma travessia e não como caminho a ser percorrido, nos colocamos na direção de observar e analisar nossas próprias práticas na tentativa de constituir o que Souza e Cury (2015) chamam de sensibilidade metodológica.

Estudar teorias e metodologias fomenta a criação de uma potência de olhar fundamental a esse processo, mas nesse artigo (na tentativa de fugir ao posicionamento do pesquisador como intelectual frente aos que estabelece como interlocutores), tratamos de uma potência oriunda de uma situação de entrevista com uma criança.

\section{Sobre um cenário em desconstrução}

O trabalho com História Oral tem sido uma prática comum a estas pesquisadoras nos últimos anos por conta de seu foco, no trabalho com diferentes temporalidades, para a produção de fontes históricas a partir da oralidade. Nesta direção, os trabalhos que tem se valido dessa metodologia, tem buscado proximidade com as discussões em torno das narrativas, interessados nos sujeitos e objetos que estas constituem.

A partir de alguns princípios historiográficos (BLOCH, 2001; ALBUQUERQUE JUNIOR, 2007), Souza (2013, p. 262) afirma que "a narrativa envolve o contar histórias, sendo uma forma própria de discurso que organiza temporalmente e significativamente eventos". No trabalho com História Oral não são as entrevistas (em gravação) necessariamente chamadas de narrativas, mas, a depender do trabalho realizado, a textualização elaborada a partir desta. Em geral, trata-se de uma história em primeira pessoa em que são constituídas ideias e um sujeito narrativo produzido na direção de quem fala (LINS, 1999). A figura do interlocutor não pode ser deixada de fora, pois quem fala, nessa perspectiva, sempre o faz em direção a alguém, ainda que este alguém não seja a pessoa em sua frente, mas, em composição com esta, a direção em que se coloca a falar.

Consideramos, inicialmente, essa narrativa como uma alternativa para a construção de fontes com crianças, sendo "[...] ela própria, num certo sentido, uma forma artesanal de comunicação. Ela não está interessada em transmitir o 'puro em si' da coisa narrada como uma informação ou um relatório" (BENJAMIN, 1994, p. 205).

Em articulação com a História Oral, estruturamos um roteiro amplo e aberto para a entrevista com Francisco, em que a temática envolvia questões acerca do seu cotidiano, com ênfase na escola, os espaços que nela frequenta e as atividades que realiza. Nos valemos de gravação em áudio e em vídeo por meio de um gravador e um celular, respectivamente. Além do Francisco, seus pais e a pesquisadora, estava também presente uma colega do grupo de pesquisa que auxiliaria no processo de gravação. Da parte do Francisco, o estranhamento surgiu com a figura estranha do gravador: olhares, toques, a fala aproximada. 
Intuindo que a condução da entrevista seria distinta das por nós já efetivadas, recorremos aos trabalhos desenvolvidos por outros pesquisadores com narrativas de crianças e, nestes, encontramos um apelo à figura de um alienígena que, sendo de outro planeta, requereria uma descrição mais detalhada sobre o aqui vivido. A compra de um objeto que representasse esse ser estranho às vivências de Francisco aliou-se a um cuidado de criar um vínculo entre este e os alienígenas já conhecidos por ele por meio do desenho animado Floogals (em que três alienígenas exploram as coisas simples do cotidiano de uma casa de humanos).

Pensávamos, até aquele momento, em realizar uma pesquisa nos distanciando dos estudos que propõe dar voz às crianças. Compreendíamos que elas já tinham voz em seu espaço e que, com a História Oral, poderíamos fazê-las ressoar em outros ambientes como, por exemplo, o da academia. A expressão "dar voz" nesse contexto, seria duplamente incômoda: primeiramente por conta de uma posição, já questionada nos estudos sobre História Oral, vinculada a uma perspectiva colonizadora e, ainda, por reforçar um sentido sinalizado por Galzerani (2005), de que

A própria acepção terminológica latina de "infância", vem de in-fans, que significa sem linguagem. No interior da tradição metafísica ocidental, não ter linguagem significa não ter pensamento, não ter conhecimento, não ter racionalidade. Neste sentido, a criança é focalizada como alguém menor, alguém a ser adestrado, a ser moralizado, a ser educado. (p. 56 e 57).

Este contexto nos motivou a pensar um trabalho em que haja efetivamente a participação de crianças, de modo que este se constitua na interação entre criança e pesquisador, ainda que de forma intermediada. Nesse sentido, como Passeggi et al. (2011), acreditamos que a construção de narrativas com crianças permite compreender os modos como praticam a escola e se relacionam com a matemática e

[...] contribuem para superar uma visão de criança como objeto de pesquisa, [anunciando] possibilidades metodológicas para a efetivação do discurso da criança como sujeito de direitos. Trata-se aqui de pensar a escola com as crianças e não pelas crianças. (p. 6).

Considerando que "a ideia de lugar da criança torna-se mais específica e geográfica à medida que ela cresce" (TUAN, 1983, p. 34), uma pesquisa que envolva a construção de narrativas com crianças de 4 e 5 anos que frequentam a escola na Educação Infantil pode nos aproximar de uma escola e uma matemática da infância, olhando não para o que chamamos de matemática e para o modo como caracterizamos a escola, mas para os significados construídos pela própria criança. Não esperávamos ou esperamos, com isso, uma volta à infância, o despertar de lembranças dessa natureza, mas a composição com elementos que nos permitam conhecer a escola que essas crianças praticam e não reconhecer nela aquela escola que nós praticamos. A impossibilidade de prever o que aparecerá nessas narrativas é uma das primeiras e importantes instabilidades geradas pelo exercício de registrar e analisar uma história criada pela criança, um modo de espacializar, em nosso caso, a escola.

Tuan (1983) traz algumas particularidades, quando considerado o contexto da criança, ao afirmar que 
Sua vitalidade para fazer as coisas e explorar o espaço não condiz com a pausa reflexiva e com a olhada para trás que fazem com que os lugares pareçam saturados de significância. A imaginação da criança é de um tipo especial. Está presa à atividade. Uma criança cavalga um pau como se estivesse sobre um cavalo de verdade, e defende uma cadeira virada como se fosse um verdadeiro castelo. [...] (p. 37)

\section{Uma entrevista, muitas subversões}

Como dito anteriormente, buscamos uma primeira articulação com a metodologia História Oral para a construção de narrativas com crianças, tomando alguns procedimentos padrões como o mapeamento e contato com possíveis depoentes (nesse caso, crianças entre 4 e 5 anos que frequentassem a Educação Infantil), a construção de um roteiro de entrevista, a gravação da entrevista, que foi realizada em áudio e vídeo, e a transcrição e textualização das fontes orais.

$O$ roteiro para as entrevistas com crianças foi pensado, primeiramente, com a exploração de uma história fictícia que incentivasse o contar direcionado a um personagem que também compunha o cenário da entrevista, trazendo algumas questões norteadoras. Essa estratégia foi mobilizada nos trabalhos de Domingues (2016), Monteiro (2015) e Rocha (2012), mas seu papel, ou melhor, o modo como esse recurso foi mobilizado nessa investigação ainda está em análise.

$\mathrm{Na}$ entrevista, a gravação foi realizada em áudio e vídeo, recursos que se mostraram indispensáveis para a construção da narrativa. A gravação em áudio foi realizada com alguns cuidados técnicos, como a localização do gravador em local próximo à criança, o que garantiu clareza no registro de toda a conversa. A gravação em vídeo foi essencial para compreender a linguagem corporal de Francisco, o que levou não somente ao esclarecimento de alguns trechos do áudio que não eram finalizados por conta da reportagem a gestos e expressões, mas à identificação de um modo próprio de compor. A percepção dessa necessidade vai ao encontro do que afirma Benjamin (1994, p. 220-221) "[...] a narração, em seu aspecto sensível, não é de modo algum o produto exclusivo da voz. Na verdadeira narração, a mão intervém decisivamente, com seus gestos [...] que sustentam de cem maneiras o fluxo do que é dito".

Essa entrevista se deu em dois momentos: no primeiro deles Francisco visualizou o boneco alienígena e já saiu correndo, dizendo precisar buscar seu astronauta para depois começar a conversa. Mostrou-se interessado na ideia de que um alienígena teria vindo para conhecer um pouco de seu modo de vida, mas alertou a pesquisadora sobre seu equívoco quando afirmou ser este um amigo dos Floogals e que eles moravam no espaço. Os Floogals não moram no espaço, dizia ele, moram em uma casa com os humanos! Francisco interessou-se em contar que sonhou estar indo ao espaço, mas encontrou uma cobra e ficou com medo; depois se interessou pelo fato do Alien (como a pesquisadora chamou o boneco alienígena) ter três olhos e afirmou que outros têm dois e outros, ainda, têm um só olho. Somente no momento da transcrição, percebeu-se a angústia da pesquisadora tentando trazer a conversa o tempo todo para o roteiro. Até esse momento, creditamos a isso os primeiros sinais de desinteresse de Francisco que, 
sem cerimônia, dá as costas às pesquisadoras e à mãe e vai brincar em outro espaço. $O$ que Francisco parece ter sentido é que não estávamos ali para compor com ele, mas para guiá-lo através de um roteiro que foi feito sem sua participação e que, portanto, não considerava seus interesses de dizer. Ele não estava sendo ouvido efetivamente.

Essa insubordinação, essa reação ou resistência não se põe a nosso ver como uma desobediência ao acordo feito inicialmente, mas como uma denúncia da violência que se impunha: um pseudo diálogo, sem escuta atenta ao que o outro tem a dizer. Essa cena nos leva ao encontro das ideias de Jorge Larrosa sobre leitura como formação. Em entrevista a Alfredo Veiga Neto, Larrosa (2007) afirma que é importante não lermos o outro buscando nós mesmos, o que queremos ouvir, o que precisamos, mas o lermos efetivamente pelo que ele é: o outro, abertos a ouvir aquilo que não previmos, não procurávamos, não estávamos interessados. Na mesma direção, Viveiros de Castro (2010), ao discutir os estudos em antropologia, assinala a necessidade do cuidado com posturas comumente encontradas:

\begin{abstract}
Vamos ver como os índios resolvem nossos problemas de relação com a natureza. E ficamos decepcionados quando vemos que os índios, primeiro, têm outros problemas e, segundo, não resolvem os nossos. [...] Portanto, só nos cabe saber quais são os problemas deles e como a relação dos problemas pode nos tirar de nossos próprios impasses, que não são os deles (p. 19).
\end{abstract}

Francisco brincando de um lado e pesquisadoras tendo que pensar em formas de insubordinar a si mesmas, suas crenças, seu roteiro bem ali: na varanda de sua casa. Seria isso uma insubordinação ou um movimento próprio da formação pela pesquisa?

No decorrer desse início de entrevista, percebemos que o Francisco era mais receptivo às perguntas da mamãe que eram baseadas no seu dia a dia, com termos e referências a lugares e ações cotidianas, que ele conhecia. Por isso, no segundo momento da entrevista, que ocorreu após o almoço, horas depois da primeira tentativa, foram os pais do Francisco que conduziram o diálogo do qual a pesquisadora foi expectadora com possibilidades de intervenção. O problema é que com todas aquelas desestabilizações, já não havia segurança em retomar o roteiro, pois este claramente não fazia mais sentido. Como agir nesse espaço? A noção de entrevista como diálogo havia sido denunciada pelo aparente engodo: pode-se chamar de diálogo quando a preocupação não está na escuta e reação, mas nos temas de um roteiro?

$\mathrm{Na}$ sequência da entrevista, Francisco falava enquanto brincava com os seus brinquedos e, em certo momento, começou a se preocupar com a partida do Alien: sairia ele voando ou simplesmente desapareceria? E quando este, sem que ele percebesse, desapareceu, se colocou a procurar embaixo das almofadas e se recusou a responder uma questão sobre sua escola afirmando que já havia acabado, pois o Alien já havia ido embora, evidenciando sua atenção para com o personagem. Por outro lado, também evidenciou um certo distanciamento, pois quando mencionado o amigo Gael (que mora em Goiás), Francisco afirma que para contar sobre a escola para ele, teria que buscar o Gael e levá-lo na escola para mostrá-la a ele, experimentar o fazer atividade, o ir no circle (roda de conversa no tapete da sala), o lanchar, o ir no play, a espera da chegada das mamães e o ir embora. 
Falamos um pouco sobre o início e o fim, falemos agora do entre! Para além das tantas questões em que essa entrevista nos provocou, é importante ressaltar o movimento do Francisco em contar uma escola como espaço de encontros entre amigos, de brincadeiras, de trocas. Narra o empoderamento do helper (ajudante da professora no dia), assumindo este uma postura mais rígida de lembrar e fazer cumprir as regras junto aos amigos. Um espaço de alegria, onde são narrados seus gostos, nenhum desgosto ("Na escola eu gosto de qualquer coisa, muitas coisas!"). A não existência de uma estrutura disciplinar parece contribuir para com o estranhamento de Francisco em relação ao termo Matemática, inicialmente mostra não ter ideia do que se trata, em outros (pela insistência da pergunta) começa a atribuir tudo à Matemática: é o balé, a roda de notícia, é quando escolhe o livro. Embora fale de círculos, quadrados, atividades envolvendo situações de adição, conte em português e em inglês progressiva e regressivamente, quando fala em contar coisas na escola, acena para sua impossibilidade de limitação: contamos histórias, notícias...

\section{Das pequenas e fundamentais insubordinações}

Observando o movimento realizado até aqui e os pressupostos que o sustentava, nos percebemos sendo arrastados pelas águas quentes-frias-claras-escuras indicadas por Sônia Clareto (2011). Não se trata da fuga da bolha, pois acreditamos que ainda nos movemos em busca de uma, mas da auto-expulsão de uma bolha específica. Nesse sentido, parece ser de maior gravidade a situação.

A noção de narrativa com a qual trabalhávamos (SOUZA, 2013), qual seja a de que esta é um discurso que organiza eventos temporal e significativamente parece não se sustentar nesse contexto em que uma única frase (como sinalizado, em conversa, por Adair Nacarato) pode ser tomada como uma narrativa.

Se vínhamos trabalhando com a ideia de que a História Oral não poderia ser tomada na perspectiva de dar voz a alguém, mas de fazê-la ressoar em espaços como o da academia, agora nos pomos a pensar seu (não) sentido. Não queremos nos por como canal de propagação de ideias, não queremos nos por a falar (num espaço que julgamos nosso) pelo outro, mas queremos falar com o outro, com a criança, como já sinalizava Passegi et al (2011). Para isso foi fundamental abandonar o primeiro exercício de textualização realizado por uma das autoras em que esta dizia do dito por Francisco, assumindo seu papel, falando por ele.

Quanto ao roteiro de entrevista, é importante ressaltar que seu preparo pode ser potente, não pelo exercício em si, mas pelo preparo do pesquisador sobre a temática e contexto sobre o qual se põe a dialogar. No caso de nossa pesquisa, entretanto, é importante sinalizar como mais importante a constituição de um vínculo com a criança, no sentido de colocar-se disposto a efetivamente ouvi-la e com ela dialogar.

Essas questões têm disparado algumas buscas importantes, entre as quais falaremos de duas: o preparo para a entrevista e o que vínhamos chamando de textualização. Uma vez aberto mão, nesse contexto, da ideia de roteiro como guia para a entrevista, temos nos colocado a pensar mais em recursos disparadores de lembranças e narrativas a serem mobilizados com as crianças: fotos da escola em que estuda; histórias 
sobre outras escolas que pudessem colocar a criança, em comparação, a falar da sua; ilustração de lugares por meio de desenhos, entre outros.

Quanto aos exercícios de transcrição e textualização, pressupostos pela História Oral, temos que: i) a transcrição foi fundamental quanto ao processo de percepção e análise não só do dito pelo entrevistado, mas das posturas e imposturas da pesquisadora e dos outros participantes daquele momento. Foi a partir, também, da análise desse material que a não escuta do outro se evidenciou, incomodou e nos moveu; ii) a textualização nos moldes comumente trabalhados na História Oral pareceu não atender ao contexto do trabalho com crianças. Se a direção é a criação de um texto com o qual o entrevistado possa se identificar, de pouco adiantaria somente a estruturação desse texto para conferência de Francisco, possivelmente por meio da leitura de seus pais. Como forma também é conteúdo, começamos a pensar em uma que possibilitasse uma identificação ou não dele com a história narrada e, ainda, a complementação dessa história. Até o momento foi pensada a criação de um livro infantil ("Uma escola de Francisco") que envolvesse a narrativa, fotos de sua escola e, ao lado de cada página, um espaço em branco para ilustrações. Pensamos que este pode ser um espaço potente para construções e complementação da narrativa por meio da exploração de seus próprios desenhos e das fotos que lhe permitirão identificação.

Os movimentos aqui narrados não nos colocam em uma busca pela maneira certa e adequada de realizar uma entrevista com crianças, mas pela problematização do nosso modo de fazê-lo e das crenças que sustentam esse fazer. Nesse sentido, nos colocamos na direção de pensar que "[...] Em seu desempenho profissional, os professores e os pesquisadores precisam mobilizar não só teorias e metodologias, mas também suas concepções, seus sentimentos e seu saber-fazer". (D'AMBRÓSIO e LOPES, 2015, p. 4)

A construção de narrativas e a alteração da própria concepção de narrativa nos leva a pensar maneiras de realizar entrevistas, nos interrogando quanto aos modos de produzi-las e analisá-las de forma que a entrevista e a própria pesquisa se constituam como espaços de diálogo com o outro. Essas inquietações têm exigido novas reflexões teóricas e metodológicas, para a criação de narrativas infantis que sinalizem não somente para modos de espacializar a escola e a matemática, mas para a exigência de uma sensibilidade metodológica por parte do pesquisador.

Nesse mesmo sentido, podemos refletir sobre o papel do pesquisador que também busca uma produção científica ética e comprometida com a qualidade de vida humana e que, portanto, assumirá um modo de investigar em que considere o respeito aos participantes da pesquisa e/ou aos documentos utilizados na investigação; perceba as delimitações da pesquisa realizada, sabendo que ela não se constitui em uma verdade única; e tenha sensibilidade e responsabilidade na utilização do saber produzido pelo outro. (D'AMBRÓSIO e LOPES, 2015, p. 4).

Essa sensibilidade metodológica, do modo como a temos pensado no Grupo HEMEP-História da Educação Matemática em Pesquisa da Universidade Federal de Mato Grosso do Sul, necessita considerar, além do respeito aos participantes da pesquisa e/ou documentos como sinalizado por D’Ambrósio e Lopes (2015), o respeito a si próprio 
enquanto pesquisador, às suas crenças e ao compromisso político que este tem ou pretende ter junto ao seu grupo de pesquisa e à Educação Matemática.

Além disso, como Kohan (2007, p. 98) acreditamos que o desenvolvimento de uma pesquisa com crianças, que envolvam seus interesses, suas práticas, suas histórias e brincadeiras, no âmbito da Educação Matemática, possa contribuir para re/pensarmos a escola e a matemática na e para a infância e

[...] quem sabe possamos encontrar um novo início para outra ontologia e outra política da infância, [...] que busca promover, desencadear, estimular nas crianças e em nós mesmo essas intensidades criadoras, disruptoras, revolucionárias, que só podem surgir da abertura do espaço, no encontro entre o novo e o velho, entre uma criança e um adulto.

\section{Considerações}

$\mathrm{Na}$ entrevista com Francisco, o percebemos insubordinando-se a um modo de interação que trazia consigo uma forma de se pensar pesquisa. Essa sua ação, ou melhor, reação dispara um processo de instabilidades fundamentais à percepção de nosso movimento na pesquisa e da necessidade de redirecionamentos urgentes.

Nesse sentido, nos colocamos junto a Francisco a insubordinarmos um modo de ação que era nosso e, assim, buscar por outras práticas na direção do falar com, que implica experimentar a potência do novo, da invenção da criança, do fazer as palavras pegarem delírio, ou seja, implica, nesse momento para nós, um afastamento da ideia de se produzir narrativas com crianças a partir de um roteiro pré-definido. Certamente nisso, e em uma sensibilidade para as questões da infância muito nos pode ajudar Manoel de Barros (2013): "As coisas não querem mais ser vistas por pessoas razoáveis: Elas desejam ser olhadas de azul, Que nem criança que você olha de ave." Ou ainda em Barros (2015),

No descomeço era o verbo.

Só depois é que veio o delírio do verbo.

O delírio do verbo estava no começo, lá,

Onde a criança diz: eu escuto a cor dos passarinhos.

A criança não sabe que o verbo escutar não

Funciona para cor, mas para som.

Então se a criança muda a função de um verbo,

ele delira.

E pois.

Em poesia que é voz de poeta,

que é a voz

De fazer nascimentos

-O verbo tem que pegar delírio.

As discussões realizadas até aqui podem ser nominadas de insubordinação criativa (como em alguns momentos fazemos) ou simplesmente apresentadas como movimento 
investigativo (como, também, optamos por fazer), não é a nomenclatura que nos interessa. Colocar-se e perceber-se em movimento é fundamental para que este participe do exercício de análise e para que se tenha como foco não somente a construção de uma dissertação ou tese, mas de um pesquisador. Disso faz parte o abrir-se a experiências, no sentido dado por Jorge Larrosa, como aquilo que nos passa, que nos toca.

É importante, entretanto, ressaltar que foi pensando nos diferentes olhares que têm produzido insubordinações criativas, que nos colocamos a discutir nossas leituras e movimentações junto a Francisco.

\section{Referências}

ALBUQUERQUE JÚNIOR, Durval Muniz. História: a arte de inventar o passado. Ensaios de teoria da história. Bauru: EDUSC, 2007. 254 p.

BARROS, Manoel. Memórias Inventadas: as infâncias de Manoel de Barros. São Paulo: Editora Planeta do Brasil, 2010.

BARROS, Manoel. Poesia Completa. São Paulo: Leya, 2015.

BENJAMIN, Walter. O narrador: considerações sobre a obra de Nikolai Leskov. In: Magia e técnica, arte e política: ensaios sobre literatura e história da cultura. São Paulo: Brasiliense, 1994, p. 197-221.

BLOCH, Mark. Apologia da História ou o Ofício do Historiador. Tradução: André Telles. Rio de Janeiro: Jorge Zahar, 2001.

CASTRO, Eduardo Viveiros de. O Anti-Narciso: lugar e função da antropologia no mundo contemporâneo. Revista brasileira de Psicanálise, São Paulo, v. 44, n. 4, p. 15-26, 2010.

CLARETO, Sônia Maria. Na travessia: construção de um campo problemático. In: CLARETO, Sônia Maria; ROTONDO, Margareth A. Sacramento; VEIGA, Ana Lygia Vieira Schil da (Org.). Entre composições: formação, corpo e educação. Juiz de Fora: Editora UFJF, 2011. $260 \mathrm{p}$.

D'AMBROSIO, Beatriz Silva; LOPES, Celi Espasandin. Insubordinação Criativa: um convite à reinvenção do educador matemático. Boletim de Educação Matemática, Rio Claro, SP, v. 29, n. 51, p. 1-17, abr. 2015.

DOMINGUES, Rafaella Maria de Varella. Era uma vez... Histórias de crianças (con)vivendo com a recidiva do câncer e seus ensinamentos sobre o cuidado. 2016. 209f. Dissertação (Mestrado em Psicologia) - Centro de Ciências Humanas, Letras e Artes, Universidade Federal do Rio Grande do Norte, Natal, 2016.

GALZERANI, Maria Carolina Bovério. Imagens entrecruzadas de infância e de produção de conhecimento em Walter Benjamin. In: FARIA, Ana Lúcia Goulart de; DEMARTINI, 
Zeila de Brito Fabri; PRADO, Patrícia Dias (Orgs.). Por uma cultura da infância: metodologias de pesquisa com crianças. $2^{\mathrm{a}}$ ed. Campinas, SP: Autores Associados, 2005, p. 49-68.

LINS, Romulo Campos. Por que discutir teoria do conhecimento é relevante para a Educação Matemática. In: BICUDO, Maria Aparecida Viggiani (Org.). Pesquisa em educação matemática: concepções e perspectivas. São Paulo: Editora UNESP, 1999. pp.75-96.

KOHAN, Walter Omar. Infância, estrangeiridade e ignorância. Belo Horizonte: Autêntica, 2007.

MONTEIRO, lêda Licurgo Gurgel Fernandes. Da educação infantil ao ensino fundamental: o que contam as crianças sobre essa travessia na cultura de escola. 2015. 138f. Dissertação (Mestrado em Educação) - Centro de Educação, Universidade Federal do Rio Grande do Norte, Natal, 2015.

PASSEGGI, Maria da Conceição et al. O que contam as crianças sobre as escolas da infância: aportes teóricos sobre as narrativas na pesquisa com crianças. In: Encontro Nacional de Didática e Práticas de Ensino - ENDIPE, 16., 2012, Campinas. Políticas de formação inicial e continuada de professores. Araraquara: Junqueira\&Marin Editores, 2012.

ROCHA, Simone Maria da. Narrativas infantis: o que nos contam as crianças de suas experiências no hospital e na classe hospitalar. 2012. 163 f. Dissertação (Mestrado em Educação) - Centro de Educação, Universidade Federal do Rio Grande do Norte, Natal, 2012.

SOUZA, Luzia Aparecida de Souza; CURY, Fernando Guedes. A Hermenêutica de Profundidade como Recurso Metodológico para as Pesquisas em História da Educação Matemática. Revista Perspectivas da Educação Matemática, Campo Grande, MS, v. 8, n. 18, p. 822-838, 2015.

SOUZA, Luzia Aparecida. Narrativas na investigação em história da educação matemática. Rev. Educ. PUC-Campinas, Campinas, v. 18, n. 3, p. 259-268, set./dez. 2013.

TUAN, Yi Fu. Espaço e lugar: a perspectiva da experiência. São Paulo: DIFEL, 1983.

VEIGA NETO, Alfredo; LARROSA, Jorge. Literatura, experiência e formação: uma entrevista com Jorge Larrosa. In: COSTA, Marisa Vorraber (Org). Caminhos Investigativos I: novos olhares na pesquisa em educação. $3^{\mathrm{a}}$ ed. Rio de Janeiro: Lamparina Editoria, 2007, p. 129-156.

Submissão: 08/08/2017

Aceite: $17 / 11 / 2017$ 